\title{
Thiamin deficiency on fetal brain development with and without prenatal alcohol exposure
}

\begin{tabular}{|r|l|}
\hline Journal: & Biochemistry and Cell Biology \\
\hline Manuscript ID & bcb-2017-0082.R1 \\
\hline Manuscript Type: & Mini Review \\
\hline Date Submitted by the Author: & $26-$ Aug-2017 \\
\hline $\begin{array}{r}\text { Complete List of Authors: } \\
\text { Is the invited manuscript for } \\
\text { consideration in a Special } \\
\text { Issue? : }\end{array}$ & $\begin{array}{l}\text { Kloss, Olena; University of Manitoba, Human Nutritional Sciences } \\
\text { Suh, Miyoung; University of Manitoba, Human Nutritional Sciences }\end{array}$ \\
\hline Keyword: & thiamin, brain, fetus, alcohol, fetal alcohol spectrum disorder \\
\hline \multicolumn{2}{|c}{} \\
\hline
\end{tabular}


Thiamin deficiency on fetal brain development with and without prenatal alcohol exposure

Olena Kloss, N. A. Michael Eskin, Miyoung Suh*

Department of Human Nutritional Sciences, St. Boniface Hospital Research Centre, University of Manitoba, Winnipeg, Manitoba, R3T 2N2

*Corresponding author:

Dr. Miyoung Suh RD, PhD

Department of Human Nutritional Sciences

R4052, St. Boniface Hospital Research Centre

Winnipeg, Manitoba

Canada R2H 2 A6

Telephone number: (204) 235-3106

E-mail: Miyoung.Suh@umanitoba.ca

Phone: 204-474-8651

Email address: Olena Kloss: umandru4@myumanitoba.ca; N Michael Eskin:

Michael.Eskin@umanitoba.ca; Miyong Suh: Miyoung.Suh@umanitoba.ca

Word count: 6138 


\begin{abstract}
Adequate thiamin levels are crucial for optimal health, through maintenance of homeostasis and viability of metabolic enzymes, which require thiamine as a co-factor. Thiamin deficiency occurs during pregnancy when dietary intake is inadequate or excessive alcohol is consumed. Thiamin deficiency leads to brain dysfunction due to its involvement in synthesis of myelin and neurotransmitters (eg. acetylcholine, $\gamma$-aminobutyric acid, glutamate), and increases oxidative stress by decreasing the production of reducing agents. The deficiency also leads to neural membrane dysfunction since thiamin is the structural of component of mitochondrial and synaptosomal membranes. Similarly, alcohol exposure in-utero leads to fetal brain dysfunction, resulting in negative effects such as Fetal Alcohol Spectrum Disorders (FASD). The outcomes of thiamin deficiency and prenatal alcohol exposure could generate negative effects synergistically on fetal development, however this area of research is understudied. This review summarizes the evidence of the potential role of thiamin deficiency in fetal brain development with and without prenatal alcohol exposure. Such evidence may influence the development of new nutrition strategies for preventing or mitigating the symptoms of FASD.
\end{abstract}

Key words thiamin, brain, fetus, alcohol, fetal alcohol spectrum disorder 


\section{Introduction}

Maternal abuse of alcohol and its effect on the developing fetus has been widely studied for several decades. Prenatal alcohol consumption is associated with Fetal Alcohol Spectrum Disorder (FASD), an umbrella terminology used to describe alcohol-related negative birth outcomes. Alcohol induces fetal damage in a variety of ways including intrauterine growth restriction (IUGR), dysmorphic features, central nervous system (CNS) damage, which results in behavioral abnormalities and poor development of social skills in the postnatal life (Ba, 2011; Esper and Furtado, 2014). Among the negative outcomes, those leading to CNS dysfunction are considered the most detrimental. These include neuronal cell loss, abnormal dendritic patterns, low brain weight and microcephaly, atypical axonal projections, and irregular proliferation of cortical neurons $(\mathrm{Ba}, 2011 ; 2013)$. Similarly, maternal thiamin deficiency has shown to be linked to IUGR, neuronal cell death, poor myelin synthesis, decreased brain weight, and other physiological abnormalities (Ba, 2011; 2009; Reddy and Ramakrishnan, 1982; Levin et al. 1985; Fattal-Valvski et al. 2009; Heinze and Weber, 1990).

One of the most common nutritional deficiencies which occur as a consequence of alcohol consumption is thiamin deficiency. Alcohol consumption in conjunction with thiamin deficiency during gestation can aggravate CNS abnormalities during fetal development (Ba, 2005). Therefore, close monitoring of this nutrient may be necessary in pregnant mothers consuming alcohol. However, the information on the role of thiamin in prenatal alcohol exposure is scarce. This review seeks to answer whether thiamin plays a crucial role during fetal brain development with prenatal alcohol exposure, as it may be critical in strategizing a potential nutrition intervention for preventing or mitigating the symptoms of FASD. 
The scientific articles for this review were searched through PubMed database. The search included the terms or combination of, thiamin, pregnancy, fetal development, brain development, alcohol, nervous system, fetus, cognitive development, vitamin B1, WernikeKorsakoff, fetal alcohol spectrum disorder/fetal alcohol syndrome, and nutrition. Since this review revisits the evidence of the proposed topic, all the studies published up to now were considered for this review.

The criteria for inclusion were: 1) published in English; 2) original research on the topic excluding review articles; 3) used human or animal models. Studies were excluded or dismissed if they only had investigated the effect of thiamin deficiency on physiological systems, but did not include CNS. In addition, any studies that did not examine the effect of thiamin deficiency during the early stages of life, such as prenatal, postnatal and lactation, were excluded.

\section{Alcohol, Thiamin Malnutrition and the Central Nervous System \\ Thiamin daily requirements}

The Dietary Reference Intake (Institute of Medicine, 2014), or daily requirement, for thiamin for adults ages 19 years and older is $1.2 \mathrm{mg}$ daily for males and $1.1 \mathrm{mg}$ daily for females, taken orally. The recommendations for pregnant women increase slightly to $1.4 \mathrm{mg}$ of thiamin per day (Institute of Medicine, 2014). The food sources of thiamin include grain products, organ meat, pork and beef, poultry, eggs, beans, fish, and nuts.

Thiamin is $\mathrm{pH}$ and heat sensitive nutrient, thus the amounts of thiamin are substantially reduced after processing and cooking of food. In addition, due to thiamin's water-solubility, the storage of thiamin is limited (approximately $30 \mathrm{mg}$ ) in various tissues of the body (Institute of 
Medicine, 2014). Thus, a constant supply of this nutrient is necessary, especially during pregnancy when fetal and maternal metabolic demands are deemed to be high.

\section{Thiamin phosphates derivatives}

Thiamin, also known as vitamin B1, is an essential, water-soluble micronutrient that is necessary for metabolism of macronutrients such as fats, proteins and carbohydrates (Martin et al. 2003). The vitamin is composed of a pyrimidine ring (2,5-dimethyl-6-aminopyrimidine) and a thiazolium ring (4-methyl-5-hydroxy ethyl thiazole) connected together by a methylene bridge. Four different forms of thiamin exist in the human body; free thiamin, thiamin-monophosphate, diphosphate, and - triphosphate (Tallaksen et al. 1992) (Figure 1). An active form is thiamin diphosphate (TPP), which represents about $80 \%$ of the total thiamin concentration in the human tissues and the blood (Tallaksen et al. 1992). High concentrations of TPP are found in the liver, kidney, myocardium, and brain, indicating high metabolic demand in these tissues (Homewood et al. 1997).

\section{Thiamin transporters}

SLC19A1, SLC19A2 and SLC19A3 are responsible for mediating the transport of thiamin. All three transporters exhibit significant structural similarity, however they use different forms of thiamin as their substrates. SLC19A1 is responsible for transporting mono- and pyro-phosphate derivatives of thiamin (Zhao et al. 2001), whereas SLC19A2 and SLC19A3 transporters are responsible for transporting thiamin in its cationic form (Dutta et al. 1999; Rajgopal et al. 2001). All transporters are ubiquitous in human body and are located on apical and basal membranes of cells (Ganapathy et al. 2004). The transporters are highly expressed in the brain, particularly SLC19A1 in the cerebral cortex and cerebellum, whereas SLC19A2 and SLC19A3 are prominent 
in hippocampus, cerebral cortex, caudate nucleus, and cerebellum (The Human Protein Atlas, 2017).

\section{Thiamin metabolism and brain functions}

Thiamin is involved as a co-enzyme in more than 24 enzymatic reactions, including pyruvate dehydrogenase, transketolase, and $\alpha$-ketoglutarate-dehydrogenase (Martin, 2003; Guerrini et al. 2007). In CNS, these enzymes are crucial for biosynthesis of myelin and neurotransmitters (eg. acetylcholine, $\gamma$-aminobutyric acid (GABA), glutamate), and the production of NADPH and glutathione to combat oxidative stress (Fattal et al. 2011; Lieber, 2000; Leevy, 1982), indicating that thiamin deficiency would lead to brain dysfunction. In addition, thiamin plays an important role in cell membrane structure and function and it acts against oxidative cytotoxicity and repairs damaged membrane sites (Ba, 2008; Fattal et al. 2011). Low TPP concentration in the brain during gestation has been reported to lead to decreased brain weight and abnormal proliferation of cortical and hippocampi neurons (Ba et al., 1999). Therefore, adequate levels of thiamin are crucial for maintaining normal brain function especially for the fetus at a vulnerable stage (Buerstatte et al. 2000).

The absorption of thiamin starts in the duodenum through an active rate-limited, carriermediated process. At the blood-brain barrier, it is transported through both passive and active mechanisms. In neurons and glial cells, thiamin is converted to its active form of TPP, which further participates in carbohydrate and lipid metabolism, as well as production of amino acids and glucose-derived neurotransmitters (glutamate and GABA) (Sechi and Serra, 2007; Vaswani, 1985; Ba, 2009, 2011; Lewohl et al. 1996). After having completed its action, thiamin and its metabolites (2-methyl-4-amino-5-pyrimidinecarboxylic acid, 4-methylthiazole-5-acetic acid) are excreted through the urinary tract to maintain thiamin homeostasis (Amos and Neal, 1970). 
At the cellular level, the major enzymes affected by thiamin deficiency are $\alpha$ ketoglutarate-dehydrogenase, transketolase, and pyruvate dehydrogenase, as described below (Figure 2):

\section{$\alpha$-Ketoglutarate-dehydrogenase activity}

During thiamin deficiency, the first impairment to occur in the brain happens in the choroid plexus, a system of cells that is responsible for production of cerebrospinal fluid (Nixon, 2008). The biochemical change occurs due to the decline in $\alpha$-ketoglutarate-dehydrogenase activity in astrocytes, which happens after about 4 days of thiamin deficiency (Sechi and Serra, 2007; Nixon, 2008). The low activity of $\alpha$-ketoglutarate-dehydrogenase leads to the decreased shift though the tricarboxylic acid (TCA) reactions, which in turn impairs brain energy metabolism and function (Lieber, 2000; Sheu and Blass, 1999). In addition, a reduction in TCA reactions leads to decreased metabolism of the potentially excitotoxic neurotransmitter glutamate, which further exacerbates brain malfunctions (Figure 2) (Sheu and Blass, 1999).

\section{Transketolase}

A decrease in the activity of transketolase appears after about 7 days of thiamin deficiency (Sechi and Serra, 2007). The reduction in transketolase activity leads to impaired flux through pentose phosphate pathway (PPP) reactions, inhibiting the production of nicotinamide adenine dinucleotide phosphate (NADPH), which is a reducing agent in glutathione synthesis (Nixon, 2008; Martin et al. 2003; Mclaren et al. 1981). In addition, an impairment of PPP reactions disturbs the production of ribose-5-phosphate, an important molecule in nucleotide synthesis, leading to inhibition of the synthesis of neurotransmitters, amino acids, and steroids, causing decreased neuronal development (Figure 2) (Mclaren et al. 1981). 
The alteration in the activity of pyruvate dehydrogenase is not established until 10 days of thiamin deficiency (Nixon, 2008; Sechi and Serra, 2007; Lieber, 2000; Munujos et al. 1996). Similar to $\alpha$-ketoglutarate-dehydrogenase, pyruvate dehydrogenase participates in the TCA cycle. Poor activity of pyruvate dehydrogenase results to the over-production of lactate by neurons and astrocytes, which increases an intracellular lactate accumulation and reduces $\mathrm{pH}$ (Munujos et al. 1996). According to animal studies, apoptotic cell death in thalamic neurons appears after about two weeks of thiamin deficiency (Munujos et al. 1996; Miyazaki et al. 2012). In addition, inactivity of pyruvate dehydrogenase leads to mitochondrial dysfunction and oxidative stress (Miyazaki et al. 2012). The major consequence of above-mentioned metabolic impairments is the loss of osmotic gradients across cell membranes, with cytotoxic edema and an increased cell-volume first in astrocytes followed by neurons (Sechi and Serra, 2007) (Figure 2).

Interestingly, these enzymatic responses to thiamin deficiency occur at different time points, however the reasons and mechanisms for this phenomenon are unknown. Disturbed enzymatic activity, resulting from thiamin deficiency, is reversible after immediate and sufficient thiamin therapy. Conversely, a delay of thiamin therapy leads to irreversible lesions in the third and fourth regions of the brain with permanent neurological damage (Chang, 2001; Kril and Haper, 2012) and a long lasting impaired language skills (Fattal et al. 2011). Therefore, early detection of thiamin deficiency is critical.

\section{Alcohol metabolism and brain functions}

The primary enzyme systems responsible for the metabolism of alcohol are cytosolic alcohol dehydrogenase (ADH), peroxisomal catalase, and microsomal cytochrome P450 (CYP2E1). Most of alcohol metabolism is occurring in the liver. At low levels, the major 
pathway of ethanol metabolism involves $\mathrm{ADH}$, which breaks down ethanol to acetaldehyde, and acetaldehyde dehydrogenase (ALDH), further catalyzing acetaldehyde to acetic acid (Cederbaum, 2012). CYP2E1 is activated by chronic ethanol consumption and plays an important role in alcohol metabolism at elevated alcohol concentrations.

Ethanol is considered to be a nutrient, with the caloric value of $7 \mathrm{kcal} / \mathrm{g}$ (Cederbaum, 2012). However, dissimilar to fat (triacylglycerides in adipose tissues and liver) and carbohydrates (glycogen in liver and muscle), which are often stored and utilized when sources of energy are low (eg, fasting), ethanol does not contain storing properties and therefore it persists in tissues until eliminated.

In the brain, alcohol is metabolized to acetaldehyde mainly by catalase and CYP2E1, then to acetate by mitochondrial ALDH2. Acetaldehyde, a highly reactive molecule that forms adducts with biogenic amines, proteins, and DNA may be at least partially responsible for the behavioural effects of ethanol (Cederbaum, 2012). After alcohol consumption, the brain preferentially uses acetate, rather than glucose, as a source of energy (Cederbaum, 2012).

\section{Factors leading to thiamin deficiency}

Thiamin deficiency occurs during inadequate dietary intake and excessive consumption of alcohol (Ba, 2005; Mayordomo et al. 1992; Carpenter et al. 2000). In developing countries, thiamin deficiency is a consequence of malnutrition, which is manifested through beriberi disease. Beriberi is characterized by malfunctions in cardiovascular system, edema, and weight loss (Carpenter et al. 2000). Conversely, in developed countries, thiamin deficiency mostly results from excessive alcohol consumption leading to Wernicke's encephalopathy in the acute phase, and Korsakoff’s psychosis in the chronic phase (Fattal et al. 2011; Dias et al. 2013). The 
neurological signs and symptoms of the disease include confusion, psychosis, ataxia, memory loss, and rapid eye movement (Martin et al. 2003; Fattal-Valevski et al. 2009; Fattal et al. 2011). The disease can be reversed with high levels of thiamin intake and appropriate diet, however if overlooked, may cause permanent brain damage, seizures, and eventually death (Fattal-Valevski et al. 2009; Fattal et al. 2011).

Chronic alcohol abuse directly affects thiamin absorption in the gastrointestinal tract, which is well documented in alcoholic patients. It results in impaired phosphorylation/ dephosphorylation mechanisms, leading to severely diminished concentrations of thiamin in its active form, TPP (Butterworth, 1995; Martin et al. 1993). Significantly lower TPP levels were found in patients who chronically abused alcohol (McLaren et al. 1981). Experimental data, using alcoholic animal models, provides evidence that after three weeks of a thiamin deficient diet, the blood level of thiamin significantly decreases, leading to an impaired function of thiamin-dependent enzymes, which consequently affects the functions of cardiovascular, central and peripheral nervous systems (Fattal-Valevski et al. 2009; Langlais et al. 1996).

\section{Alcohol, Thiamin Malnutrition and the Developing Central Nervous System}

It is well known that the most dynamic CNS developmental changes are occurring during prenatal period of life, as rapid neuronal growth, cell differentiation and proliferation occur during this period (Mayodormo et al. 1992). Therefore adequate nutrient levels are especially critical during fetal development. Moreover, the demands of physiological changes during pregnancy lead to an increased need for various nutrients in order to meet the requirements of a mother and a fetus. Maternal malnutrition is a strong pre-determinant of preterm birth, low weight baby, still birth, and poor developmental outcomes (Black, 2001). The 
effects of thiamin deficiency on prenatal and postnatal nervous system development with and without ethanol exposure during pregnancy are summarized in Tables 1, 2 and 3.

\section{Maternal thiamin deficiency}

\section{Animal Studies}

Experimental data in animal models indicates that maternal thiamin deficiency may lead to spinal cord malfunctions, deficits of the brain enzymes, psychomotor and sensory abilities, poor nerve conduction and myelinogenesis (Oliveira et al. 2007; Butterworth, 1995; Ba, 2005; de Freitas-Silva et al. 2010; Levin et al. 1985; Vaswani, 1985; Reddy and Ramakrishnan, 1982) (Table 1). A study conducted by Reddy and Ramakrishnan (1982), reported that thiamin deficiency during pregnancy and lactation had an effect on brain lipid concentrations in the offspring, causing structural deficits in the white matter, where dense myelin is found. Subsequent analyses of the effect of thiamin deficiency on the brain biochemistry documented reduced levels of galactolipids, phospholipids, plasmalogens, gangliosides, acetylcholine (Ach), and GABA contents (Vaswani, 1985; Reddy and Ramakrishnan, 1982; de Freitas-Silva et al. 2010; Kulkarni and Gaitonde, 1983), which are all involved in neuronal signaling in brain network. The biochemical abnormalities caused by thiamin deficiency are preceded by physiological malfunctions such as deformity in posture, arched back, and hind limb paralysis and low body weight. It also leads to cognitive deficits including low learning speed and special tasks in rats (Levin et al. 1985; de Freitas-Silva et al. 2010; Reddy and Ramakrishnan, 1982) (Table 1).

A body of early research on thiamin deficiency mainly focuses on the activity of thiamin dependent enzyme, transketolase. Authors stated that neurodevelopmental malfunctions seen in 
experimental thiamin deficiency are the result of depletion of transketolase (Tallaksen et al. 1992; Geel and Dreyfus, 1974). Geel and Dreyfus (1974) examined the effect of thiamin deficiency on transketolase activity in rats during two different critical periods of development. Transketolase activity declined during the first 5 days of life. Cerebellum, diencephalon, and brain stem were found to be particularly sensitive to thiamin deficiency. After 5 weeks of thiamin deficiency animals exhibited reduced motor activity, ataxia, and arched back (Geel and Dreyfus, 1974).

In a more recent study, thiamin deficiency during pregnancy initiated a significant reduction in the voltage-dependent $\mathrm{K}+$ membrane conductance and considerably suppressed the transient A-type $\mathrm{K}+$ currents leading to neuronal cell death in rats' offspring (Oliveira et al. 2007). Ba (2005) also stated that thiamin deficiency during nervous system development, interferes with cellular proliferation, differentiation and migration, leading to massive neuronal death. The author speculated that these observations are attributable to the role of thiamin in energy metabolism (Ba, 2005). The effects of thiamin deficiency on nervous system are transferable to the effects of malnutrition, because pair-feeding animal experiments produce very similar outcomes (Ba, 2005; Ba, 2013; Fournier and Butterworth, 1989).

Another study investigated the effect of biotin deficiency in conjunction with thiamin deficiency on producing abnormalities seen in FASD (Levin et al. 1985) (Table 1). Fetuses exposed to biotin deficient diet demonstrated mild forms of intrauterine growth restriction (IUGR), whereas fetuses exposed to biotin-thiamin deficient diet demonstrated severe IUGR. In addition, authors observed dramatic differences in brain, placental, and body size between the groups. They recommended extrapolation of their findings to humans as it may assist in 
determining the etiology of FASD consequently contributing to possible beneficial nutrition interventions (Levin et al., 1985).

\section{Human Studies}

Only a few reports have been documented on the effects of thiamin deficiency and negative developmental outcomes in utero and in infancy (Table 2). There was one incidence of infant encephalopathy that occurred in Israel in 2003 (Fattal-Valevlski et al. 2009). Several infants were admitted in pediatric intensive care units with the symptoms of lethargy, vomiting, seizures, and coma. Investigation of the case revealed that all infants were consuming a nondairy, soy-based, thiamin-deficient infant formula $(<0.5 \mathrm{ug} / \mathrm{g}$ vs $385 \mathrm{ug}$ as claimed in the formula). The symptoms disappeared upon consumption of thiamin supplementation. The authors followed the infants 25-39 months later to investigate the development of language skills. Children who consumed thiamin-deficient formula exhibited delayed language development, auditory comprehension, expressive communication and motor development compared to healthy controls. While there appeared to be a strong link between thiamin deficiency and delayed language development, the authors outlined several limitations to this investigation. Due to the introduction of possible thiamin containing foods, not all children started at the same baseline. In addition, the authors were unable to determine precisely when the soy-based formula was used during child's early development, resulting in the lack of correlation between the developmental parameters, timing, and duration of exposure to the thiamin-deficient formula. However, when they did a follow-up study of the affected children 5 years later, 97\% of them had language impairment and 10\% of them had conceptual disability (Fattal et al. 2011). Regardless, this follow-up study indicated that thiamin deficiency experienced during the critical 
developmental stage may have long lasting effects in later life, especially language impairment (Fattal-Valevski et al. 2009; Fattal et al. 2011).

Another case of infantile thiamin deficiency was recorded in groups of mothers and infants, from a westernized Caucasian community in Australia (Jeffrey et al. 1985). Findings revealed that thiamin deficiency was high in 'near-miss' sudden infant death syndrome (SIDS) infants and their mothers, and in siblings of SIDS (Jeffrey et al. 1985), however there is no robust data that confirms the relationship between thiamin deficiency and SIDS incidences (Table 2).

One more report on thiamin deficiency during pregnancy revealed that thiamin concentrations are significantly lower in the blood cells of mothers whose pregnancy was complicated by the IUGR (Heinze and Weber, 1990) (Table 2). The IUGR-pregnancy patients were experiencing increased risk of preterm labor, fetal acidosis and fetal hypoxia (Heinze and Weber, 1990). While authors speculated that such outcomes were not due to thiamin deficiency alone, they suggested that thiamin supplementation may reduce the severity of IUGR, especially in the later stages of gestation (Heinze and Weber, 1990).

\section{Maternal alcohol intake and thiamine deficiency}

\section{Animal Studies}

Several animal experiments investigated the effects of alcohol and thiamin during pregnancy and lactation. Maternal thiamin deficiency and alcohol toxicity alter neuronal environment and morphology, decrease cell differentiation, resulting in an inability of the brain to respond to internal and external changes and create new neuronal pathways (Guerrini et al. 2007; Ba et al. 1999; Ba, 2011; 2005; Butterworth, 1993). A study examining ethanol-thiamin 
metabolic interaction, found that ethanol interferes with thiamin metabolism, resulting in impaired cell differentiation and membrane developmental processes mostly during prenatal, perinatal-, and postnatal stages (Ba, 2011) (Table 3). The author suggested that ethanol-thiamin interactions are at its peak during the perinatal stage as it primarily affects neuronal cell differentiation, which occurs during this stage (Ba, 2011).

Pre-natal alcohol exposure and thiamin deficiency, induced through a thiamin-deficient diet, are found to be a risk factor for still births in pregnant Wistar rats (Ba, 2009). Still birth deaths were apparent and accounted for $84 \%$ in the ethanol exposed and thiamin-deficient group (Ba, 2009) (Table 3). In addition, prenatal thiamin deficiency without ethanol exposure increased spontaneous abortion by $40 \%$. Thiamin administration reversed the rate of spontaneous abortions in the ethanol exposed and thiamin-deficient group. The author speculated that such deleterious pregnancy outcomes were not due to thiamin deficiency per se but rather due to the synergistic effects of both lack of thiamin and alcohol intake. In addition, the author hypothesized that still births, exhibited only by thiamin-deficient rats, were due to interferences with insulin growth factors (IGF-I and IGF-II) involved in promotion of cellular proliferation and differentiation, which control early gestation events. Lack of thiamin during gestation interferes with IGF-I and IGF-II leading to IUGR and impaired cellular proliferation and differentiation, thus compromising fetal viability. In addition, thiamin deficiency induced decreased gangliosides (Vaswani, 1985), complex sphingolipids abundant in brain, which could have led to the impaired cell proliferation.

Several other studies examined the interference of ethanol with thiamin metabolism during various stages of gestation. The results showed that both gestational thiamin deficiencies and ethanol exposure throughout all 3 trimesters produce various neuronal cell deficit, reduced 
brain size, increased neuronal cytotoxicity, delayed motor and cognitive functions, and increased neonatal anxiety (Ba et al. 1999; Ba, 2005, 2011). Thiamin administration, during developmental ethanol exposure and thiamin deficiency, partially restored neuroanatomical damage (Ba, 2009, 2011) (Table 3).

Human Studies

While no studies have examined alcohol intake and thiamin deficiency during pregnancy, it is common that patients who abuse alcohol have lower intakes of macro- and micro-nutrients compared to the dietary reference requirements (Guerrini et al. 2007; Young et al. 2014). Common vitamin and mineral deficiencies in alcohol abusing population include vitamin E, folate, vitamin $\mathrm{C}$, vitamin $\mathrm{D}$, riboflavin, vitamin B12, thiamin, zinc selenium, and several trace minerals (Guerrini et al. 2007; Young et al. 2014, Butterwoth et al. 1993). Up-to-date, there are no studies that directly investigated maternal or fetal plasma thiamin levels, due to ethical and social concerns, however about $30-80 \%$ of alcohol abusers develop thiamin deficiency due to poor diet, reduced absorption, vomiting, and direct inhibition of thiamin activating enzymes (Butterworth, 1993; Homewood et al. 1997; Lieber, 2000; Guerrini et al. 2007).

While nutritional status during pregnancy has been a study target, there are no recent reports on the effects of alcohol on thiamin levels in pregnant women. For human infants, thiamin deficiency occurs mainly in mothers who have low thiamin status during pregnancy and lactation (Fattal et al. 2011; Guerrini et al. 2007). More research in human population is required to establish the thiamin-ethanol relationship and its effect on the CNS in developing fetus.

\section{Conclusion}

Determination of risk and protective factors for FASD is paramount for the development of successful prevention and intervention strategies. Various nutritional factors interact with 
alcohol, potentially exacerbating or protecting against FASD. Pre-clinical animal studies provide evidence that prenatal ethanol exposure increases oxidative stress and impairs mitochondrial function and ATP production. Conversely, prenatal vitamin and mineral supplementation alleviates ethanol-induced teratogenicity reducing the severity of CNS dysfunction (Esper and Furtado, 2014; Ba, 2011). A few animal studies had shown that thiamin administration during the perinatal stage of pregnancy has been able to reverse neurological damage done by maternal alcohol toxicity in combination with thiamin deficiency (Ba et al. 1999; Ba, 2009; 2011). These findings suggest that thiamin deprivation in alcoholic women may contribute to the severity of FASD and alcohol-related developmental deficits.

Inadequate maternal nutrition plays a significant role in FASD outcomes since nutrients are required to support fetal and maternal health. Heavy alcohol consumption is the leading cause of thiamin deficiency. While little is known about the contribution of thiamin deficiency to FASD outcomes, undernutrition is a common factor contributing to a majority of cases of FASD. Therefore, it is crucial to investigate the role of thiamin in mitigating FASD and other alcohol related birth outcomes. Understanding the mechanisms of thiamin involvement in brain development during gestational alcohol exposure is critical to efficiently plan and develop a nutritional strategy for FASD.

\section{Acknowledgements}

Supported by the Manitoba, Innovation, Energy \& Mines and Canada Israel International Fetal Alcohol Consortium. A part of this manuscript by OK won the Dr. Elizabeth Feniak Award for Excellence in Technical Writing in the graduate category in 2015, Canadian Home Economics Foundation. 


\section{References}

Alexander-Kaufman, K., and Harper, C. 2009. Transketolase: Observations in alcohol-related brain damage research. Int. J. Biochem. Cell Biol. 41: 717-720. doi:10.1016/j.biocel.2008.04.005. PMID:18490188.

Ambrose, M. L., Bowden S.C., and Whelan, G. 2001. Thiamin treatment and working memory function of Alcohol-Dependent people: Preliminary findings. Alcohol. Clin. Exp. Res. 25: 112116. PMID:11198705.

Amos, W.H., and Neal, R.A. 1970. Isolation and Identification of 3- (2'-Methyl-4'-amino Spyrimidylmethyl)-4-methylthiazole-Sacetic Acid (Thiamine Acetic Acid) and 2-Methyl-40 amino-5-formylaminomethylpyrimidine as metabolites of thiamine in the rat. J Biol. Chem. 245: 5643-5648. PMID:5472363.

Ba, A., Seri, B.V., Aka, A.J., Glin, L., and Tako, A. 1999. Comparative effects of developmental thiamine deficiencies and ethanol exposure on the morphometry of the CA3 pyramidal cells. Neurotoxicol Teratol. 5: 579-586. PMID:10492392.

Ba, A. 2005. Functional vulnerability of developing central nervous system to maternal thiamine deficiencies in the rat. Dev. Psychobiol. 47: 408-414. doi:10.1002/dev.20105.

PMID:16284970.

Ba, A. 2009. Alcohol and B1 vitamin deficiency-related stillbirths. J. Matern. Fetal. Neonatal. Med. 22: 452-457. doi:10.1080/14767050802609775. PMID:19530005.

Ba, A. 2011. Comparative effects of alcohol and thiamine deficiency on the developing central nervous system. Behav. Brain. Res. 225: 235-242. doi:10.1016/j.bbr.2011.07.015. PMID:21784107.

Ba, A. 2013. Perinatal thiamine deficiency-induced spontaneous abortion and pup-killing responses in rat dams. Nutr. Neurosci. 16: 69-77. doi:10.1179/1476830512Y.0000000032. PMID:22889588.

Ba, A., Seri, B.V., and Han S.H. 1996. Thiamine administration during chronic alcohol intake in pregnant and lactating rats: Effects on the offspring neurobehavioural development. Alcohol. Alcohol. 31: 27-40. PMID:8672172.

Ba, A., N'Douba, V., D'Almeida, M., and Seri, B.V. 2005. Effects of maternal thiamine deficiencies on the pyramidal and granule cells of the hippocampus of rat pups. Acta Neurobiol. Exp. 65: 387-398. PMID:16366391.

Ba, A., Seri, B.V., Aka, K.J., Glin, J., and Tako, A. 1999. Comparative effects of developmental thiamine deficiencies and ethanol exposure on the morphometry of the CA3 pyramidal cells. Neurotoxicol. Teratol. 21: 579-586. PMID:10492392. 
Black, R.E. 2001. Micronutrients in pregnancy. Br. J. Nutr. 85: 193-197. PMID:11509110.

Buerstatte, C.R., Behar, K.L., Novotny, E.J., and Lai, J.C. 2000. Brain regional development of the activity of $\alpha$-ketoglutarate dehydrogenase complex in the rat. Dev. Brain Res. 125: 139-145. PMID:11154769.

Butterworth, R.F. 1993. Maternal thiamine deficiency a factor in intrauterine growth retardation. Ann. N. Y. Acad. Sci. 678: 325-329. PMID:8494275.

Butterworth, R.F. 1995. Pathophysiology of alcoholic brain damage: Synergistic effects of ethanol, thiamine deficiency and alcoholic liver disease. Met. Brain Dis. 10: 1-8.

PMID:7596324.

Carpenter, K.J. 2000. Beriberi, white rice, and vitamin B: A disease, a cause, and a cure. Berkeley, CA; University of California Press.

Cederbaum, A.I. 2012. Alcohol metabolism. Clin. in Liv. Dis, 4: 667-685. doi:10.1016/j.cld.2012.08.002. PMID:23101976.

Chang, N., Kim, E., Kim, S.Y., Jeong, B.S., and Chang, N. 2001. Study of the relation between proton magnetic resonance spectroscopy metabolites in the brain regions and the B vitamin status in alcoholics. Nutr. Res. 21: 811-820.

de Freitas-Silva, D.M., Resende, L.de.S., Pereira, S.R., Franco, G.C., and Ribeiro, A.M. 2010. Maternal thiamine restriction during lactation induces cognitive impairments and changes in glutamate and GABA concentrations in brain of rat offspring. Beh. Brain Res. 211: 33-40. doi:10.1016/j.bbr.2010.03.002. PMID:20211656.

Dias, F.M.V., de Freitas Silva, D. M., Costa de Proença Doyle, C., and Ribeiro, A.M. 2013. The connection between maternal thiamine shortcoming and offspring cognitive damage and poverty perpetuation in underprivileged communities across the world. Med. Hypotheses. 80: 13-16. doi:10.1016/i.mehy.2012.09.011. PMID:23098375.

Dutta, B., Huang, W., Molero, M., Kekuda, R., Leibach, F.H., Devoe, L.D., Ganapathy, V., and Prasad, P.D. 1999. Cloning of the human thiamine transporter, a member of the folate transporter family. J. Biol. Chem. 274: 31925-31929. PMID:10542220.

Esper, L.H., and Furtado, E.F. 2014. Identifying maternal risk factors associated with Fetal Alcohol Spectrum Disorders: a systematic review. Eur. Child Adolesc. Psychiatry, 23: 877-889. doi:10.1007/s00787-014-0603-2. PMID:25164262.

Fattal, I., Friedmann, N., and Fattal-Valevski. A. 2011. The crucial role of thiamine in the development of syntax and lexical retrieval: A study of infantile thiamine deficiency. Brain 6 1720-1739. doi:10.1093/brain/awr068.PMID:21558277. 
Fattal-Valevski, A., Azouri-Fattal, I., Greenstein, Y.J., Guindy, M., Blau, A., and Zelnik, N. 2009. Delayed language development due to infantile thiamine deficiency. Dev. Med. Child Neurol. 51: 629-634. doi:10.1111/j.1469-8749.2008.03161.x. PMID:19191836.

Fattal-Valevski, A., Kesler, A., Sela, B., Nitzan-Kaluski, D., Rotstein, M., Mesterman, R., and Toledano-Alhadef, H. 2005. Outbreak of life-threatening thiamine deficiency in infants in Israel caused by a defective soy-based formula. Pediatrics, 115: 233-238. doi: 10.1542 /peds.20041255. PMID:15687431.

Ferreira, M.P., and Weems, M.K.S. 2008. Alcohol consumption by aging adults in the United States: Health benefits and detriments. J. Am. Diet. Assoc. 108: 1668-1676. doi:10.1016/j.jada.2008.07.011. PMID:18926132.

Fournier, H., and Butterworth, R.F. 1989. Effects of maternal thiamine deficiency on the development of thiamine-dependent enzymes in regions of the rat brain. Neurochem. Int. 15: 439-444. PMID:20504518.

Ganapathy, V., Smith, S.B., and Prasad, P.D. 2004. SLC19: the folate/thiamine transporter family. Eur. J. Physiol. 447: 641-646. doi:10.1007/s00424-003-1068-1. PMID:14770311.

Geel, S.E., and Dreyfus, P.M. 1974. Thiamine deficiency encephalopathy in the developing rat. Brain Res. 76: 435-445. PMID:4855187.

Guerrini, I., Thomson, A.D., and Gurling, H.D. 2007. The importance of alcohol misuse, malnutrition and genetic susceptibility on brain growth and plasticity. Neurosci. Biobehav. R. 31: 212-220. doi:10.1016/j.neubiorev.2006.06.022. PMID:16908066.

Harper, C., and Matsumoto, I. 2005. Ethanol and brain damage. Curr. Opin. Pharmacol. 5: 73-78. doi:10.1016/j.coph.2004.06.011. PMID:15661629.

Heinze, T., and Weber, W. 1990. Determination of thiamine (vitamin B 1) in maternal blood during normal pregnancies and pregnancies with intrauterine growth retardation. $\mathrm{Z}$. Ernährungswiss. 29: 39-46. PMID:2333720.

Homewood, J., Bond, N.W., and MacKenzie, A. 1997. The effects of single and repeated episodes of thiamin deficiency on memory in alcohol-consuming rats. Alcohol, 14: 81-91. PMID:9014028.

Homewood, J.B., and Bond, N.W. 1999. Thiamin deficiency and Korsakoff's syndrome: Failure to find memory impairments following nonalcoholic Wernicke's encephalopathy. Alcohol, 19: 75-84. PMID:10487391.

Hoyumpa, A.M. Jr. 1980. Mechanisms of thiamin deficiency in chronic alcoholism. Am. J. Clin. Nutr. 33: 2750-2761. PMID:6254354. 
Institute of Medicine (IOM). 2014. Dietary reference intakes (DRIs).

Jeffrey, H.E., McCleary, B.V., Hensley, W.J., and Read, D.J. 1985. Thiamine deficiency-a neglected problem of infants and mothers-possible relationships to sudden infant death syndrome. Aust. N. Z. J. Obstet. Gyn. 25: 198-202. PMID:3866557.

Kril, J., and Harper, C. 2012. Neuroanatomy and neuropathology associated with Korsakoff's syndrome. Neuropsych. Rev. 22: 72-80. doi:10.1007/s11065-012-9195-0. PMID:22528862.

Krishnan, H.R., Amul J.S., Teppen, T.L., Berkel, T.D.M., and Pandey, C.H. 2014. The epigenetic landscape of alcoholism. Int. Rev.Neurobiol. 115: 75-116. doi:10.1016/B978-0-12801311-3.00003-2. PMID:25131543.

Kulkarni, A.B., and Gaitonde, B.B. 1983. Effects of early thiamin deficiency and subsequent rehabilitation on the cholinergic system in developing rat brain. J. Nutr. Sci. Vitaminol. 29: 217225. PMID: 6886841.

Langlais, P., Zhang, S., and Savage, L. 1996. Neuropathology of thiamine deficiency: An update on the comparative analysis of human disorders and experimental models. Metab. Brain Dis. 11: 39-54. PMID:8815388.

Latt, N.D., and Dore, G. 2014. Thiamine in the treatment of Wernicke encephalopathy in patients with alcohol use disorders. Intern. Med. J. 44: 911-915. doi:10.1111/imj.12522.

PMID:25201422.

Leevy, C.M. 1982. Thiamin deficiency and alcoholism. Ann. N. Y. Acad. Sci. 378: 316-326. PMID:7044226.

Levin, S., Roecklein, B., and Mukherjee, A. 1985. Intrauterine growth retardation caused by dietary biotin and thiamine deficiency in the rat. Res. Exp. Med. 185: 375-381. PMID:4059664.

Lewohl, J.M., Crane, D.I., and Dodd, P.R. 1996. Alcohol, alcoholic brain damage, and gaba a receptor isoform gene expression. Neurochem. Int. 29: 677-684. PMID:9113136.

Lieber, C.S. 2000. Alcohol: Its metabolism and interaction with nutrients. Ann. Nutr. Rev. 20: 295-430. doi:10.1146/annurev.nutr.20.1.395. PMID:10940340.

Martin, P. R., Singleton, C. K., and Hiller-Sturmhofel, S. 2003. The role of thiamine deficiency in alcoholic brain disease. Alcohol Res. Health, 27: 134-139. PMID:15303623.

Martin, P.R., Mccool, B.A., and Singleton, C.K. 1993. Genetic sensitivity to thiamine deficiency and development of alcoholic organic brain disease. Alcohol. Clin. Exp. Res. 17: 31-37. PMID:8452206. 
Martin, P., Levin, S., Impeduglia, G., Choe, Y., Karanian, J., and Mukherjee, A. 1989. Thiamine deficiency in utero alters response to ethanol in adulthood. Psychopharmacology, 97: 253-256. PMID:2498935.

Mayordomo, F., Renau-Piqueras, J., Megias, L., Guerri, C., Iborra, F.J., Azorin, L., and Ledig, M. 1992. Cytochemical and stereological analysis of rat cortical astrocytes during development in primary culture. effect of prenatal exposure to ethanol. Int. J. Dev. Biol. 36: 311-321.

PMID:1326314.

Mclaren, D.S., Docherty, M.A., and Boyd, D.H. 1981. Plasma thiamin pyrophosphate and erythrocyte transketolase in chronic alcoholism. Am. J. Clin. Nutr. 34: 1031-1033.

PMID:7234733.

Miyazaki, A., Sano, M., Fukuwatari, T., and Shibata, K. 2012. Effects of ethanol consumption on the B-group vitamin contents of liver, blood and urine in rats. Br. J. Nutr. 108: 1034-1041. doi:10.1017/S0007114511006192. PMID:22172166.

Munujos, P., Coll-Cantí, J., Beleta, J., González-Sastre, F., and Gella, F.J. 1996. Brain pyruvate oxidation in experimental thiamin-deficiency encephalopathy. Clin. Chim. Acta. 255: 13-25. PMID:8930410.

Nixon, P.F. 2008. Glutamate export at the choroid plexus in health, thiamin deficiency, and ethanol intoxication: Review and hypothesis, (report). Alcohol. Clin. Exp. 32: 1339-1349. doi:10.1111/j.1530-0277.2008.00727.x. PMID:18616670.

Oliveira, F.A., Galan, T.D., Ribeiro, A.M., and Cruz, J.S. 2007. Thiamine deficiency during pregnancy leads to cerebellar neuronal death in rat offspring: Role of voltage-dependent $\mathrm{K}+$ channels. Brain Res. 1134: 79-86. doi:10.1016/j.brainres.2006.11.064. PMID:17196946.

Petrovic, M.M., Scepanovic, L., Rosic, R., and Mitrovic, D.M. 2008. Properties of thiamin transport in isolated perfused hearts of chronically alcoholic guinea pigs this article is one of a selection of papers published in the special issue bridging the gap: Where progress in cardiovascular and neurophysiologic research meet. Can. J. Physiol. Pharmacol. 86: 160-165. doi:10.1139/Y08-013. PMID:18418424.

Pincus, J.H., and Wells, K. 1972. Regional distribution of thiamine-dependent enzymes in normal and thiamine-deficient brain. Exp. Neurol. 37: 495-501. PMID:4650890.

Rajgopal, A., Edmondnson, A., Goldman, I.D., and Zhao, R. 2001. SLC19A3 encodes a second thiamine transporter ThTr2. Biochim. Biophys. Acta. 1537: 175-178. PMID:11731220.

Reddy, T.S., and Ramakrishnan, C.V. 1982. Effects of maternal thiamine deficiency on the lipid composition of rat whole brain, gray matter and white matter. Neurochem. Int. 6: 495-499. PMID:20487904. 
Rees, E., and Gowing, L.R. 2013. Supplementary thiamine is still important in alcohol dependence. Alcohol Alcohol, 48: 88-92. doi:10.1093/alcalc/ags120. PMID:23161892.

Ryan, A. S., Hurlbut, D.E., Lott, M.E., Ivey, F.M., Fleg, J., Hurley, B.F., and Goldberg. A.P. 2001. Insulin action after resistive training in insulin resistant older men and women. J. Am. Geriatr. Soc. 49: 247-253. PMID:11300234.

Sanjeeva R.T., and Ramakrishnan, C.V. 1982. Effects of maternal thiamine deficiency on the lipid composition of rat whole brain, gray matter and white matter. Neurochem. Int. 4: 495-499. PMID:20487904.

Sechi, G., and Serra, A. 2007. Wernicke's encephalopathy: new clinical settings and recent advances in diagnosis and management. Lancet Neurol. 6: 442-455. doi:

10.1016/S1474-4422(07)70104-7. PMID:17434099.

Sheu, K.F., and Blass, J.P. 1999. The $\alpha$-ketoglutarate dehydrogenase complex. Ann. N. Y. Acad. Sci. 893:61-78. PMID:10672230.

Tallaksen, C.M. E., Bohmer, T., and Bell, H. 1992. Blood and serum thiamin and thiamin phosphate esters concentrations in patients with alcohol dependence syndrome before and after thiamin treatment. Alcohol. Clin. Exp. Res. 16: 320-325. PMID:1317136.

The Human Protein Atlas. 2017. SciLifeLab. Retreived from: http://www.proteinatlas.org /ENSG00000135917-SLC19A3/cancer

Vaswani, K K. 1985. Effect of neonatal thiamine and vitamin a deficiency on rat brain gangliosides. Life Sci. 37: 1107-1115. PMID:4033352.

Young, J.K., Giesbrecht H.E., Eskin, MN., Aliani, M., and Suh, M. 2014. Nutrition implications for fetal alcohol spectrum disorder. Adv. Nutr. 5: 675-692. doi:10.3945/an.113.004846.

PMID:25398731.

Zahr, N. M., Luong, R., Sullivan, E.D., and Pfefferbaum, A. 2010. Measurement of serum, liver, and brain cytokine induction, thiamine levels, and hepatopathology in rats exposed to a 4-day alcohol binge protocol. Alcohol. Clin. Exp. Res. 34: 1858-1870. doi:10.1111/j.15300277.2010.01274.x. PMID:20662804.

Zhao, R., Gao, F., Wang, Y., Diaz, GA., Gelb, BD., and Goldman, ID. 2001. Impact of the reduced folate carrier on the accumulation of active thiamin metabolites in murine leukemia cells. J. Biol. Chem. 276: 1114-1118. doi:10.1074/jbc.M007919200. PMID:11038362. 
Table 1. Studies on thiamin deficiency on prenatal- and postnatal outcomes in animal models

\begin{tabular}{lllc}
\hline $\begin{array}{l}\text { Animal } \\
\text { models }\end{array}$ & $\begin{array}{l}\text { Diet duration/ } \\
\text { age at measurement }\end{array}$ & Treatments & Main outcomes \\
\end{tabular}

\section{Thiamine deficiencies on brain lipid compositions}

\begin{tabular}{|c|c|c|c|c|}
\hline $\begin{array}{l}\text { Charles Foster } \\
\text { Albino rats }\end{array}$ & $\begin{array}{l}\text { Dams fed TD diet } \\
\text { from GD } 14 \text { to PD } 21 \\
\text { Pups measured at PD } 21\end{array}$ & $\begin{array}{l}\text { 1. Control }(25 \% \\
\text { protein }) \\
\text { 2. TD diet } \\
\text { 3. Pair-fed Control }\end{array}$ & $\begin{array}{l}\text { TD: } \downarrow \text { body weight }(34 \%) \text { and brain weight }(75 \%) \text {; abnormalities in } \\
\text { posture, arched back, and hind limb paralysis from } 16^{\text {th }} \text { day of lactation; } \\
\downarrow \text { galactolipids }(27 \%) \text {, phospholipids }(11 \%) \text {, and plasmalogens }(15 \%) \\
\text { in the whole brain; } \\
\downarrow \text { gray matter }(18 \%), \downarrow \text { white matter }(44 \%) \text {. } \\
\text { Pair-fed: } \downarrow \text { body weight }(42 \%) \text { and brain weight }(83 \%) \text {; } \downarrow \text { galactolipids } \\
(23 \%) \text {, phospholipids }(15 \%) \downarrow \text { cholesterol }(14 \%) \text {; } \\
\downarrow \text { gray matter }(12 \%), \downarrow \text { white matter }(33 \%)\end{array}$ & $\begin{array}{l}\text { Reddy \& Ramakrishnan, } \\
1982\end{array}$ \\
\hline $\begin{array}{l}\text { Charles Foster } \\
\text { Albino rats }\end{array}$ & $\begin{array}{l}\text { Dams fed TD diet } \\
\text { from GD } 14 \text { to PD } 21 \\
\text { Pups measured at PD } 21\end{array}$ & $\begin{array}{l}\text { 1. Control diets } \\
\text { 2. Vitamin A } \\
\text { deficiency diet } \\
\text { 3. TD diet }\end{array}$ & TD: $\downarrow$ gangliosides $(49 \%)$ & Vaswani, 1985 \\
\hline
\end{tabular}

\section{Thiamine deficiencies on brain neurochemistry}

\begin{tabular}{|c|c|c|c|c|}
\hline Rats & $\begin{array}{l}\text { Male pups fed TD diet from PD } 1 \text { to } \\
\text { PD } 31 \text { and PD } 75 \\
\text { Male pups measured at PD } 31 \text { and } \\
\text { PD } 75\end{array}$ & $\begin{array}{l}\text { 1. Control } \\
\text { 2. TD diet }(10 \% \\
\text { thiamin) }\end{array}$ & $\begin{array}{l}\text { TD at PD31: } \downarrow \text { body weight, learning speed } \\
\text { TD at PD75: } \downarrow \text { body weight, } \downarrow \text { glutamate GABA contents, }\end{array}$ & de Freitas-Silva et al., 2010 \\
\hline Albino rats & $\begin{array}{l}\text { Dams fed TD diet during } \\
\text { gestation+lactation, GD } 7 \text { to PD } 28 \text {; } \\
\text { Dams fed TD diet during lactation, } \\
\text { PD 1-PD } 21 \\
\text { Pups measured at PD } 21 \text { and PD } 28\end{array}$ & $\begin{array}{l}\text { 1.TD gestation } \\
\text { +lactation } \\
\text { 2.TD lactation }\end{array}$ & $\begin{array}{l}\text { TD gestation+lactation: } \downarrow \text { brain ACh at } \\
\text { PD } 21 \text { (24\%) and PD } 28(39 \%) \\
\text { TD lactation: } \downarrow \text { brain ACh at PD28 }\end{array}$ & Kulkarni \& Gaitonde, 1983 \\
\hline
\end{tabular}


Thiamine deficiencies on neuronal development

\begin{tabular}{|c|c|c|c|c|}
\hline Wistar rats & $\begin{array}{l}\text { Dames fed TD diet from Pre-Preg } 3 \\
\text { to GD 21; GD 7-GD 17; PD 1-PD } 25 \\
\text { Pups measured at GD 21, GD 17, PD } \\
25\end{array}$ & $\begin{array}{l}\text { 1. Control } \\
\text { 2. Prenatal TD } \\
\text { 3. Perinatal TD } \\
\text { 4. Postnatal TD }\end{array}$ & $\begin{array}{l}\text { Prenatal TD: } \downarrow \text { exploratory activity, emotional reaction; } \downarrow \text { hind paws } \\
\text { lifting reflex, } \\
\text { wire grasping times; } \downarrow \text { leap and crawling, execution and of tail-flick. } \\
\text { All parameters were significant ( }<<0.0001 \text { ) } \\
\text { Perinatal TD: } \downarrow_{\text {hind paws lifting reflex, wire grasping times; } \downarrow \text { leap }} \\
\text { and crawling, execution and of tail-flick. All parameters were } \\
\text { significant ( }<<0.0001 \text { ) } \\
\text { Postnatal TD: } \downarrow \text { exploratory activity, emotional reaction; } \\
\downarrow \text { leap and crawling, execution and of tail-flick All parameters were } \\
\text { significant ( }<<0.0001)\end{array}$ & $\mathrm{Ba}, 2005$ \\
\hline Wistar rats & $\begin{array}{l}\text { Dams fed TD diet from GD } 0 \\
\text { to PD } 7 \\
\text { Pups measured at or PD } 7\end{array}$ & $\begin{array}{l}\text { 1. TD diet } \\
\text { 2. Control }\end{array}$ & $\begin{array}{l}\text { TD: } \downarrow \text { body weight and brain weight; } \\
\text { loss of neuronalviability; } \\
\uparrow \text { neurocytotoxicity, } \downarrow \text { voltage-dependent } \mathrm{K}+\text { membrane conduction, } \\
\downarrow \text { transient A-type } \mathrm{K}+\text { currents }\end{array}$ & Oliveira et al., 2007 \\
\hline
\end{tabular}

\section{Thiamine deficiencies on brain enzyme activity}

\begin{tabular}{|c|c|c|c|c|}
\hline $\begin{array}{l}\text { Sprague- } \\
\text { Dawley rats }\end{array}$ & $\begin{array}{l}\text { Dams fed TD diet at GD } 14 \\
\text { Pups measured at or PD } 5,13,45\end{array}$ & $\begin{array}{l}\text { 1. Control } \\
\text { 2. TD diet } \\
\text { 3. Pair-fed } \\
\text { control } \\
\text { 4. Thiamin } \\
\text { replenishment } \\
(101 \mu \mathrm{g} / 100 \mathrm{~g} \\
\text { body weight) }\end{array}$ & $\begin{array}{l}\text { TD: region-selective delays in the establishment of activities of } \\
\text { thiamine-dependent enzymes; } \boldsymbol{\Downarrow} \text { Pyruvate dehydrogenase activity in } \\
\text { cerebral cortex were }(20 \% \mathrm{P}<0.05) ; \boldsymbol{\downarrow} \alpha \text {-ketoglutarate dehydrogenase } \\
\text { activity in cerebral cortex }(30 \% \mathrm{P}<0.05) ; \boldsymbol{\downarrow} \text { transketolase activity was } \\
\text { in cerebral cortex, cerebellum and brainstem. } \\
\text { Thiamine replenishment: restored defective enzyme activities to normal } \\
\text { level }\end{array}$ & $\begin{array}{l}\text { Fournier \& Butterworth, } \\
1989\end{array}$ \\
\hline $\begin{array}{l}\text { Long-Evans } \\
\text { Rats }\end{array}$ & $\begin{array}{l}\text { Dames fed TD diet from } \\
\text { GD } 14 \text { - PD } 25 \\
\text { Dams measured at PD } 25\end{array}$ & $\begin{array}{l}\text { 1. Control: ad lib } \\
\text { 2. } \mathrm{TD}(0.5 \mathrm{mg} / \mathrm{kg} \text { of } \\
\text { thiamin })\end{array}$ & 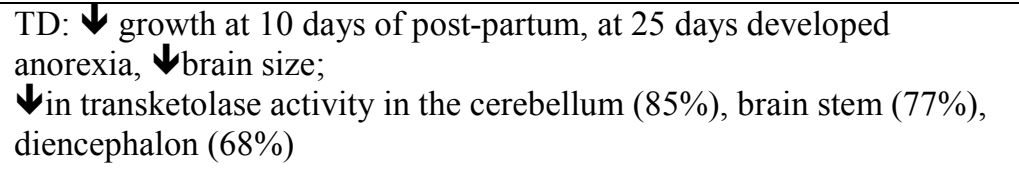 & Geel \& Dreyfus, 1974 \\
\hline
\end{tabular}




\section{Thiamine deficiencies on fetal development}

$\begin{array}{lll}\text { Sprague- } & \text { Dams fed biotin deficient } & \text { 1. Control: ad lib } \\ \text { Dawley rats } & \text { (BD) diet vs BD+TD diet } & \text { 2. BD diet }(0.07 \mathrm{mg} / \mathrm{kg}) \\ & \text { GD 1-GD 21 } & \text { 3. BD }(0.07 \mathrm{mg} / \mathrm{kg})+\mathrm{TD}(0.43 \\ & \mathrm{mg} / \mathrm{kg}) \text { diet }\end{array}$

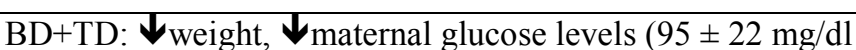

compared to controls $131 \pm 30 \mathrm{mg} / \mathrm{dl}), \boldsymbol{\downarrow}$ fetus size, placental, brain

and liver size, $\boldsymbol{\uparrow}$ brain-liver ratio.

BD: did not show any overt signs of illness

Thiamine deficiencies on behavior activity

\begin{tabular}{lll}
\hline Long & Dams fed TD diet from GD 8 & 1. Control: ad lib \\
Evans rats & to PD 10 and PD 18 & 2. Prenatal TD \\
& & 3. Postnatal TD
\end{tabular}

Pups measured at PD 10 and PD

3. Postnatal TD

Prenatal TD: $\downarrow$ active avoidance learning $(\mathrm{p}<0.05)$

Bell \& Stewart, 1979

18

TD, thiamine deficiency; GD, gestational day; PD, postnatal day; Pre-Preg, pre-pregnancy; BD, biotin deficiency; ad lib, ad libitum 
Table 2. Studies on thiamin deficiency on prenatal- and postnatal outcomes in humans

\begin{tabular}{|c|c|c|c|c|}
\hline Subjects & $\begin{array}{l}\text { Diet duration/age } \\
\text { at measurement }\end{array}$ & Treatment & Outcomes & Author \\
\hline $\begin{array}{l}\text { Mothers and } \\
\text { infants }\end{array}$ & $\begin{array}{l}\text { Mothers and infants at term; vs mothers } \\
\text { and older infants; } \\
\text { vs mothers and 'near-miss' SIDS } \\
\text { infants;-vs SIDS infants }\end{array}$ & N/A & $\begin{array}{l}\text { TD status: high in 'near-miss' SIDS infants }(40 \%) \text { and their } \\
\text { mothers }(52 \%) \text {, and in siblings of SIDS }(50 \%) \text {. }\end{array}$ & Jeffrey et al., 1985 \\
\hline Children & $\begin{array}{l}\text { Children previously exposed to TD soy } \\
\text { based formula during } 1^{\text {st }} \text { year of life } \\
\text { Measured at age of } 25-39 \text { months }\end{array}$ & $\begin{array}{l}\text { Control (other milk } \\
\text { sources) vs Case ( } \mathrm{n}=20 \text {, } \\
\text { soy based TD formula) }\end{array}$ & $\begin{array}{l}\text { TD: } \boldsymbol{\uparrow} \text { vomiting, irritability, lethargy; } \\
\boldsymbol{\downarrow} \text { expressive language, } \boldsymbol{\Downarrow} \text { auditory comprehension, } \boldsymbol{\Downarrow} \text { Mental } \\
\text { Developmental Index Score, } \boldsymbol{\Downarrow} \text { motor skills; All significant } \\
(\mathrm{p}<0.001) .\end{array}$ & Fattal-Valevski et al., 2008 \\
\hline Pregnant women & Healthy vs mothers having IUGR & N/A & $\begin{array}{l}\text { IUGR mothers: } \downarrow \text { thiamine levels in blood cells, } \\
\boldsymbol{\uparrow} \text { vaginal bleeding }(48 \%), \boldsymbol{\uparrow} \text { fetal acidosis }(26 \%)\end{array}$ & Heinze \& Weber, 1990 \\
\hline Children & $\begin{array}{l}\text { Children previously exposed to TD soy } \\
\text { based formula during } 1^{\text {st }} \text { year of life } \\
\text { Measured at age } 5-7 \text { years }\end{array}$ & $\begin{array}{l}\text { Control }(\mathrm{n}=35 \text {, fed } \\
\text { thiamine rich diet) vs } \\
\text { Case }(\mathrm{n}=59 \text {, fed TD } \\
\text { formula during } 1 \text { st year } \\
\text { of life.) }\end{array}$ & TD: $\boldsymbol{\uparrow}$ language impairment (96.6\%) & Fattal et al., 2011 \\
\hline
\end{tabular}

TD, thiamine deficiency; IUGR, intrauterine growth restriction; SIDS, sudden infant death syndrome 
Table 3. Studies of thiamine deficiency on prenatal and postnatal outcomes with ethanol exposure during pregnancy

\begin{tabular}{|c|c|c|c|c|}
\hline $\begin{array}{l}\text { Animal } \\
\text { models }\end{array}$ & $\begin{array}{l}\text { Diet duration/ } \\
\text { age at measurement }\end{array}$ & Thiamine/ Ethanol dose & Outcomes & Author \\
\hline $\begin{array}{l}\text { Sprague- } \\
\text { Dawley } \\
\text { Rats }\end{array}$ & $\begin{array}{l}\text { Dams fed TD diet from GD } \\
\text { 2-GD } 21 \\
\text { Male pups measured at PD } 7 \\
\text { mo with EtOH exposure }\end{array}$ & $\begin{array}{l}\text { Control }(4.06 \mathrm{mg} \text { thiamin } / \mathrm{kg} \text {, diet }) \\
\text { vs TD }(0.11 \mathrm{mg} \text {, thiamin } / \mathrm{kg} \text {, diet } \\
\text { EtOH treatment: } \\
\text { EtOH }(25 \mathrm{mg} / \mathrm{L} \text { and } 38 \mathrm{mg} / \mathrm{L}) \text { to male } \\
\text { pups }\end{array}$ & TD: $\uparrow$ total body water, $\boldsymbol{\uparrow}$ BECs, $\uparrow$ behavioral impairment & Martin et al., 1989 \\
\hline Wistar rats & $\begin{array}{l}\text { Dams fed TD diet during } \\
\text { from GD 3-GD 21; GD 17- } \\
\text { PD 10; PD1- PD 21 } \\
\text { Pups measured at GD 21, PD } \\
\text { 10, and PD } 21\end{array}$ & $\begin{array}{l}\text { 1. Control } \\
\text { 2. Prenatal TD } \\
\text { 3. Perinatal TD } \\
\text { 4. Postnatal TD } \\
\text { EtOH treatments: } \\
\text { 1. } 12 \% \text { EtOH/water exposed } 60 \text { days } \\
\text { before mating and continuing } \\
\text { throughout gestation and lactation. } \\
\text { 2. } 12 \% \text { EtOH/water +thiamine } \\
\text { hydrochloride }(0.2 \mathrm{~g} / \mathrm{L})\end{array}$ & $\begin{array}{l}\text { Nuclear size neuronal cells } \downarrow \text { in all treatment groups }(p< \\
0.0001) \text {; } \\
\text { Perinatal TD: cell deficit+microencephaly } \\
\begin{array}{l}\text { EtOH: } \downarrow \text { CA3 pyramidal nuclear size than in the three } \\
\text { treatments of thiamine deficiency }(p<0.005) \text {; }\end{array} \\
\begin{array}{l}\text { EtOH +thiamine: partially restored the mean nuclear size, but } \\
\text { remained smaller than in the controls; }\end{array}\end{array}$ & Ba et al., 1999 \\
\hline
\end{tabular}




\begin{tabular}{|c|c|c|c|c|}
\hline Wistar rats & $\begin{array}{l}\text { Dams fed TD diet from Pre- } \\
\text { Preg 3-GD 21; GD 7-PD 10; } \\
\text { PD 1- PD } 21 \\
\text { Pups measured at GD 21, PD } \\
\text { 10, PD } 21\end{array}$ & $\begin{array}{l}\text { 1.Control } \\
\text { 2. Prenatal TD } \\
\text { 3. Perinatal TD } \\
\text { 4. Postnatal TD } \\
\\
\text { EtOH treatments: } \\
1.12 \% \text { EtOH/water (via water) exposed } \\
60 \text { days before mating and continuing } \\
\text { throughout gestation and lactation; } \\
2.12 \% \text { EtOH/ water+thiamine } \\
\text { Hydrochloride }(0.2 \mathrm{~g} / \mathrm{L} \text { via water) } \\
\text { exposed } 1 \text { week before mating till } \\
\text { weaning }\end{array}$ & 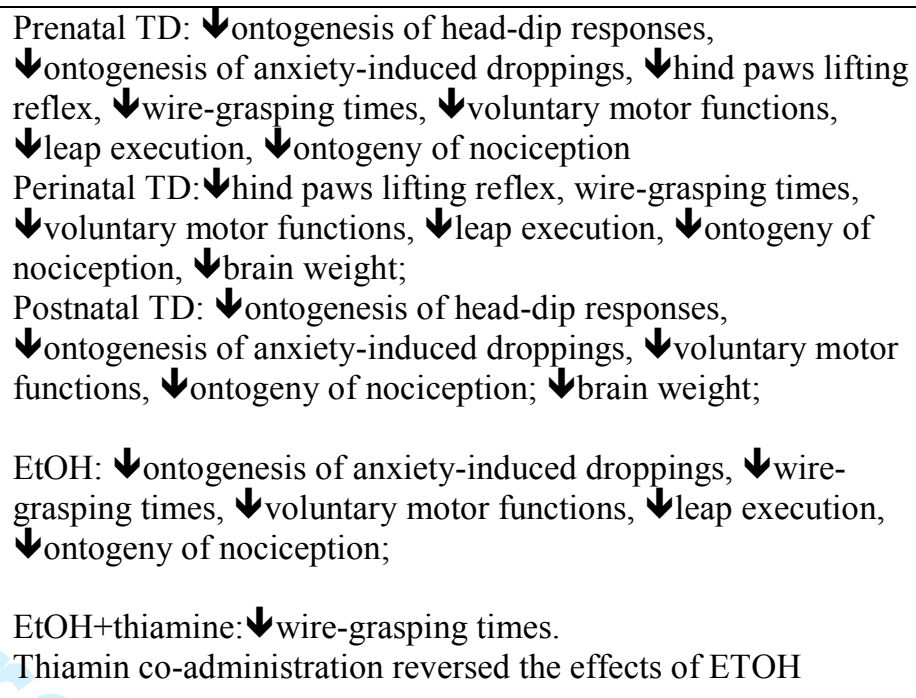 & $\mathrm{Ba}, 2011$ \\
\hline Wistar rats & $\begin{array}{l}\text { Dams fed TD diet from Pre- } \\
\text { Preg 3-GD 21; GD 10-PD10; } \\
\text { PD 1- PD } 21 \\
\text { Pups measured at GD 21, PD } \\
\text { 10, PD21 }\end{array}$ & $\begin{array}{l}\text { 1.Controls } \\
\text { 2. Prenatal TD } \\
\text { 3. Perinatal TD } \\
\text { 4.Postnatal TD } \\
\text { EtOH treatments: } \\
12 \% \text { EtOH/water (via water) exposed to } \\
60 \text { days before mating and continuing } \\
\text { throughout gestation and lactation } \\
\text { dams. }\end{array}$ & 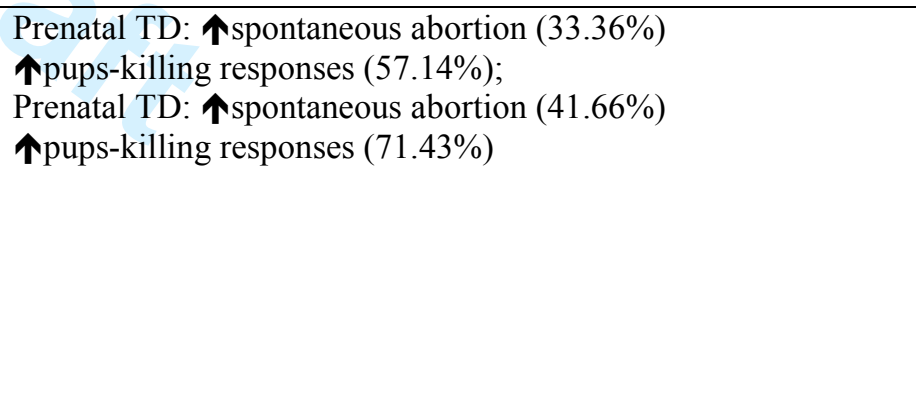 & $\mathrm{Ba}, 2013$ \\
\hline
\end{tabular}

TD, thiamine deficiency; GD, gestational day; PD, postnatal day; Pre-Preg, pre-pregnancy; EtOH, ethanol 
Fig.1. Forms of thiamin found in human tissues

Fig.2. Summary of increased blood alcohol concentration on thiamin pyrophosphate impacting neuronal cells. An increase in blood alcohol concentration diminishes thiamin pyrophosphate levels, which leads to impairments in pyruvate dehydrogenase (PDH), and $\alpha$-ketoglutarate dehydrogenase $(\alpha-\mathrm{KDH})$. Low levels of these enzymes reduce flux through the tricarboxylic acid (TCA) cycle resulting in elevated cytosolic acidity, and decreased energy and neurotransmitter metabolism. Disturbed PDH activity also leads to mitochondria dysfunction and increases oxidative stress resulting in cytotoxic edema together with higher acidity. The PDH also leads to decreased acetyl Co-A for the synthesis of myelin, sterols and other neurotransmitters. In addition, low thiamine pyrophosphate diminishes transketolase, which disturb pentose phosphate pathway, inhibiting NADPH production, glutathione production and nucleotide synthesis. 
<smiles>Cc1cncc(Cc2c(C)sc(CCO)c2C)c1N</smiles>

a) Free thiamin
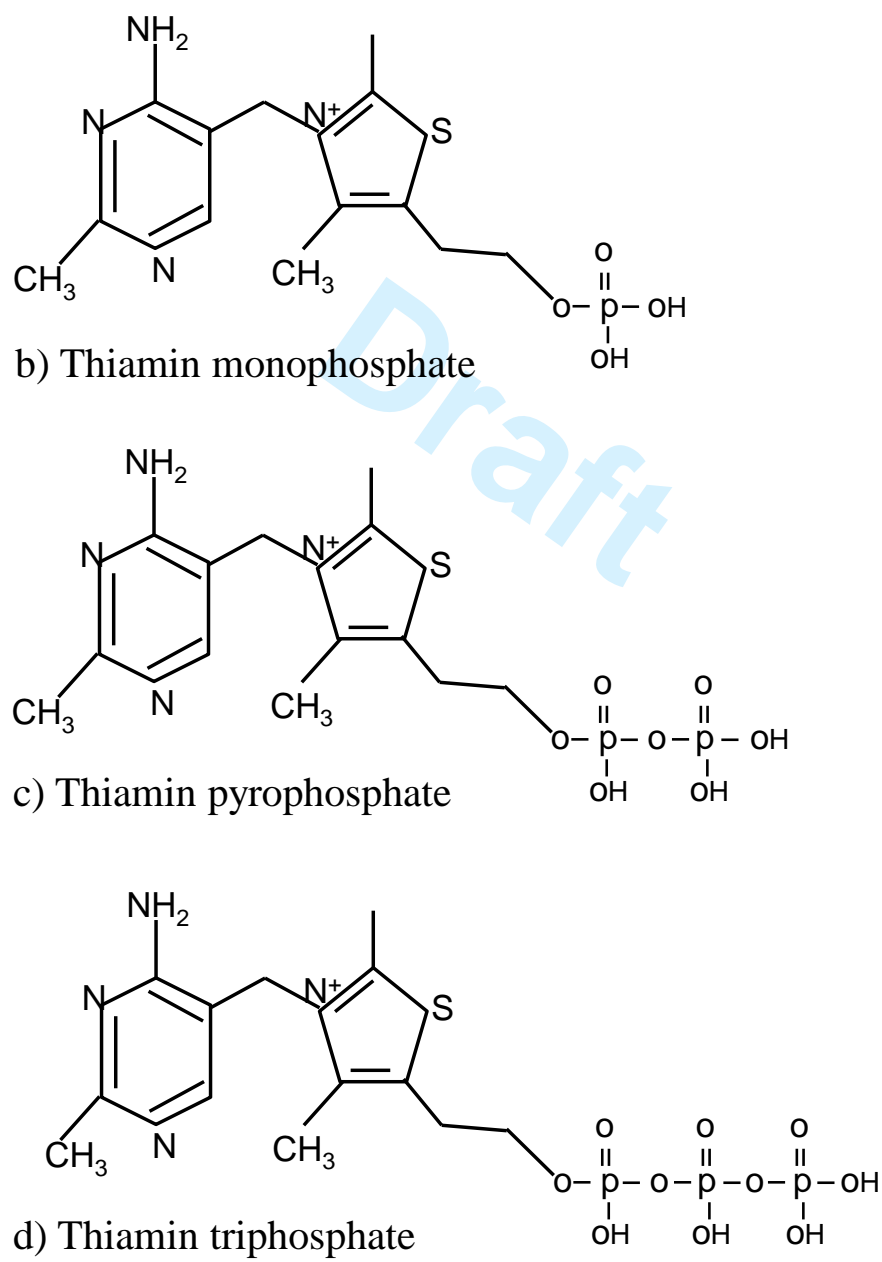

https://mc06.manuscriptcentral.com/bcb-pubs 


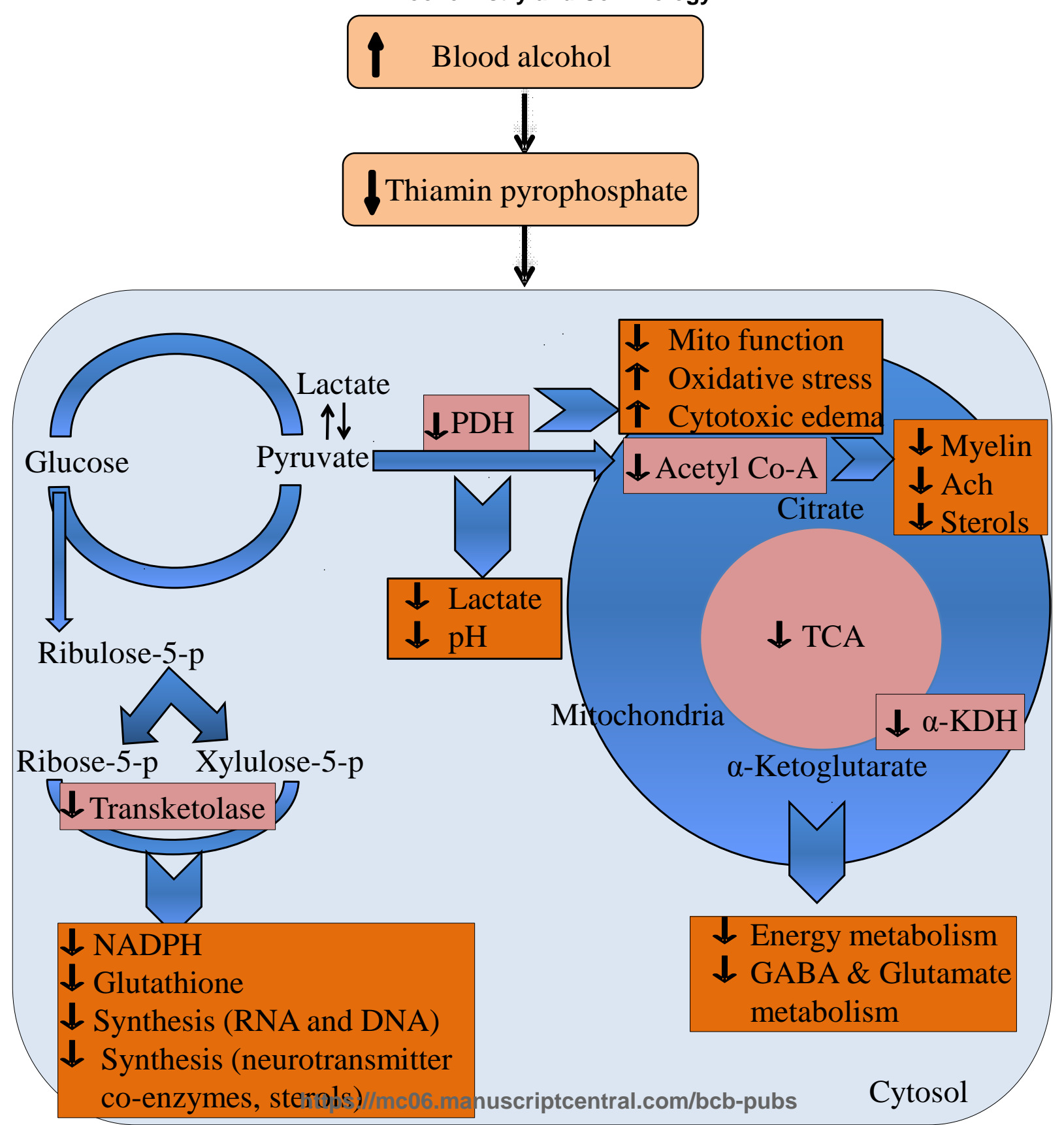

Fig. 2 